\title{
Pulse wave velocity in primary hyperparathyroidism and effect of surgical therapy
}

\author{
Jan Rosa ${ }^{1}$, Ivan Raska Jr${ }^{1}$, Dan Wichterle ${ }^{2}$, Ondrej Petrak ${ }^{1}$, Branislav Strauch ${ }^{1}$, Zuzana Somloova ${ }^{1}$, \\ Tomas Zelinka ${ }^{1}$, Robert Holaj ${ }^{1}$ and Jiri Widimsky $\mathrm{Jr}^{1}$
}

The study was aimed at investigating the arterial stiffness assessed by aortic pulse wave velocity (PWV) in the presence of primary hyperparathyroidism (PH), with and without concomitant hypertension. Subsequently, we examined the effect of parathyroidectomy (PTX) on arterial stiffness. A total of 28 patients with PH and concomitant hypertension, and 16 with $\mathrm{PH}$ without hypertension were investigated in comparison with 28 essential hypertensive patients and 18 healthy controls, respectively. Patients were matched for age, blood pressure (BP), body mass index, lipid profile and fasting glucose. Six months after PTX, 15 patients were examined again (hypertensive as well as normotensive). PWV was obtained using the SphygmoCor applanation tonometer (AtCor Medical, West Ryde, Australia). PWV was significantly higher in patients with PH and hypertension when compared with patients with essential hypertension (10.1 vs. $8.5 \mathrm{~m} \mathrm{~s}^{-1}, P=0.013$ ). PWV remained significant even after adjustment for age and BP $(P=0.02)$. Similarly, PWV was significantly higher in $\mathrm{PH}$ patients without hypertension in comparison with healthy controls $\left(7.6\right.$ vs. $\left.5.8 \mathrm{~m} \mathrm{~s}^{-1}, P<0.001\right)$. Six months after surgery, in addition to a normalization of calcium metabolism, a significant decrease in systolic BP (131 vs. $123 \mathrm{~mm} \mathrm{Hg}, P=0.004)$ and PWV (9.1 vs. $\left.8.5 \mathrm{~m} \mathrm{~s}^{-1}, P=0.024\right)$ was observed. After adjusting for BP reduction, the decrease in PWV appeared non-significant. Our data indicate that PH increases PWV as a marker of arterial stiffness, in both hypertensive and non-hypertensive patients. However, neither the calcium serum level nor the parathyroid hormone level has been associated with PWV. Specific treatment by PTX significantly decreases PWV, which may be determined primarily by improved BP control after surgery.

Hypertension Research (2011) 34, 296-300; doi:10.1038/hr.2010.232; published online 25 November 2010

Keywords: arterial stiffness; primary hyperparathyroidism; pulse wave velocity

\section{INTRODUCTION}

Primary hyperparathyroidism $(\mathrm{PH})$ is frequently associated with arterial hypertension. ${ }^{1}$ The prevalence of high blood pressure (BP) varies between 20 and $80 \%{ }^{2,3}$ The association of $\mathrm{PH}$ and hypertension remains unclear, but it has been attributed to the combined effect of persistently high levels of serum calcium, parathyroid hormone (PTH) and other vasoactive calcium-regulating hormones, and/or renal function impairment. ${ }^{4}$ Furthermore, excessive occurrence of cardiovascular complications and mortality has been reported in patients with $\mathrm{PH}^{3,5,6}$

Few data are available with regard to large-artery properties in $\mathrm{PH}$. Several studies have investigated endothelial dysfunction, ${ }^{7,8}$ augmentation of peripheral pulse waveform ${ }^{9,10}$ or the aortic stiffness index ${ }^{11}$ in PH. So far, only one study has examined pulse wave velocity (PWV) as a measure of arterial stiffness in normotensive patients with $\mathrm{PH} .{ }^{12}$ To our knowledge, reports are missing on PWV evaluation in patients with $\mathrm{PH}$ with concomitant hypertension. $\mathrm{PWV}$ is considered to be a biomarker of cardiovascular risk that extends beyond classic risk factors. ${ }^{13}$
It remains to be determined whether parathyroidectomy (PTX) might result in BP reduction, recovery of large-artery properties and improvement of cardiovascular morbidity and mortality. ${ }^{12,14-16}$

Our study sought to investigate the arterial stiffness assessed by carotid-femoral PWV in the presence of PH. Specifically, we investigated the hypothesis that PWV is increased in patients with $\mathrm{PH}$ with or without concomitant hypertension when compared with patients with essential hypertension (EH) and healthy controls; that is, independently of prevailing arterial BP. We also examined the effect of PTX on arterial stiffness.

\section{METHODS}

Study population

A total of 28 patients with $\mathrm{PH}$ and concomitant hypertension (PHHT), $16 \mathrm{PH}$ patients without hypertension (PHNT), 28 patients with EH and 18 normotensive control subjects were studied. Six months after successful PTX, 15 patients (11 hypertensive and 4 without hypertension) were investigated again. All subjects were women. Each participant provided written informed consent, and the study was approved by the local Ethics Committee.

\footnotetext{
13rd Department of Internal Medicine, General Faculty Hospital, First Medical Faculty, Charles University, Prague, Czech Republic and 22nd Department of Internal Medicine, General Faculty Hospital, First Medical Faculty, Charles University, Prague, Czech Republic

Correspondence: Dr J Rosa, 3rd Department of Internal Medicine, General Faculty Hospital, First Medical Faculty, Charles University, U Nemocnice 2, Prague 128 08 , Czech Republic.

E-mail: jan.rosa@|f1.cuni.cz

Received 23 February 2010; revised 21 August 2010; accepted 23 August 2010; published online 25 November 2010
} 
The diagnosis of $\mathrm{PH}$ was established by demonstrating hypercalcemia and hypophosphatemia in the presence of elevated intact PTH concentrations. ${ }^{17}$ Ultrasonography and/or Tc-99 m MIBI scintigraphy of the parathyroid glands was performed before surgery. Only patients with confirmed parathyroid adenoma were included in the study. Subjects were considered hypertensive if their clinical BP was repeatedly higher than $140 / 90 \mathrm{~mm} \mathrm{Hg}$ or if they were being treated with antihypertensive drugs. Hypertensive patients with $\mathrm{PH}$ were treated with $\beta$-blockers (17), calcium channel blockers (9), ACE inhibitors/ sartans (12) or loop diuretics (4). Because this treatment might influence the renin-angiotensin-aldosterone system, neither plasma renin activity nor aldosterone levels were evaluated in this group. The diagnosis of $\mathrm{EH}$ was made by exclusion of the most common forms of secondary hypertension (primary aldosteronism, pheochromocytoma, Cushing's syndrome, renal parenchymal disease and renovascular hypertension) and when there were no signs of $\mathrm{PH}$. EH patients were treated with calcium channel blockers and/or $\alpha$-blockers. Normotensive controls were recruited from subjects without a history of hypertension or cardiovascular disease who were not under treatment with antihypertensive medication.

\section{Pulse wave velocity}

All subjects underwent the PWV assessment with the applanation tonometer Sphygmocor (AtCor Medical). Subjects were studied by a single examiner after overnight fasting and after a 15-min resting period, during which the patient was in a supine position in a quiet room. Aortic PWV was assessed by the time difference between pulse wave upstrokes, which were consecutively measured at the right common carotid artery and right femoral artery, then aligned by the ECG-based trigger. The 'percentage pulse height algorithm' was used to locate the foot of the pulse waves.

\section{Blood pressure measurements}

Brachial BP values were obtained immediately before the arterial stiffness assessment using an oscillometric sphygmomanometer (Dinamap, Critikon, Tampa, FL, USA).

\section{Laboratory tests}

All biochemical parameters were analyzed using multi-analyzers (Hitachi 717, Boehringer Mannheim, Mannheim, Germany) in the central laboratory of the institute. Serum-intact PTH was determined using an electrochemiluminescence immunoassay. The Cockcroft-Gault formula was used to estimate the glomerular filtration rate.

\section{Statistical analysis}

Depending on the normal/non-normal distribution (Shapiro-Wilks W-test) of individual variables, the results are shown as means \pm s.d. or medians (interquartile range). Between-group comparisons were performed by two-tailed $t$-test for independent samples. The Kruskal-Wallis test was used for nonnormally distributed variables. Pearson's correlation analysis and multivariate regression analysis (stepwise forward method) were applied to assess the relationship among PWV and clinical/laboratory parameters. For betweengroup PWV comparisons, a multivariate regression model was used to adjust for confounding indices. Differences between patients before and after the operation were analyzed by $t$-tests for dependent samples or Wilcoxon's pair test for non-normally distributed variables, as well as by analysis of variance for repeated measurements. A $P$-value $<0.05$ was considered to be significant. The statistical analysis was performed by STATISTICA software version 8 (StatSoft, Tulsa, OK, USA).

\section{RESULTS}

The basic characteristics of studied groups are shown in Table 1. There were no significant differences in age, duration of hypertension, body mass index, lipid profile or fasting glucose or creatinine levels between the PHHT and EH groups. PHHT patients had higher potassium levels and, as expected, higher levels of calcium and lower phosphate levels. PWV was significantly higher in PHHT patients when compared with $\mathrm{EH}$ patients $\left(10.1\right.$ vs. $\left.8.5 \mathrm{~m} \mathrm{~s}^{-1}, P=0.013\right)$. No significant difference in clinical BP between the groups (136/77 vs. 135/

Table 1 Characteristics of studied subjects

\begin{tabular}{|c|c|c|c|c|c|c|}
\hline & PHHT & $E H$ & P-value & PHNT & NCS & P-value \\
\hline Number of subjects $(n)$ & 28 & 28 & - & 16 & 18 & - \\
\hline Age (years) & $65 \pm 10$ & $63 \pm 10$ & 0.410 & $52 \pm 14$ & $48 \pm 15$ & 0.431 \\
\hline Duration of hypertension (years) & $9(5-15)$ & $5(1-15)$ & 0.454 & - & - & - \\
\hline BMI $\left(\mathrm{kg} \mathrm{m}^{-2}\right)$ & $28.3 \pm 4.7$ & $27.4 \pm 4.8$ & 0.527 & $24.6 \pm 3.4$ & $25.3 \pm 3.8$ & 0.560 \\
\hline Plasma sodium $\left(\mathrm{mmol} \mathrm{I}^{-1}\right)$ & $141 \pm 3$ & $142 \pm 4$ & 0.339 & $141 \pm 3$ & $141 \pm 2$ & 0.376 \\
\hline Plasma potassium (mmol $\left.{ }^{-1}\right)$ & $4.5 \pm 0.5$ & $4.2 \pm 0.4$ & 0.003 & $4.4 \pm 0.3$ & $4.2 \pm 0.3$ & 0.032 \\
\hline Plasma chloride (mmol $\mathrm{I}^{-1}$ ) & $105 \pm 4$ & $106 \pm 3$ & 0.481 & $106 \pm 2$ & $106 \pm 3$ & 0.569 \\
\hline Plasma calcium (mmol I-1) & $2.81 \pm 0.22$ & $2.35 \pm 0.14$ & $<0.001$ & $2.73 \pm 0.15$ & $2.34 \pm 0.11$ & $<0.001$ \\
\hline Plasma phosphorous (mmol ${ }^{-1}$ ) & $0.81 \pm 0.16$ & $1.14 \pm 0.17$ & $<0.001$ & $0.85 \pm 0.13$ & $1.11 \pm 0.18$ & $<0.001$ \\
\hline iPTH $\left(\mathrm{mmoll}^{-1}\right)$ & $18.1 \pm 11.5$ & - & - & $20.2 \pm 13.8$ & - & - \\
\hline Total plasma cholesterol $\left(\mathrm{mmol} \mathrm{I}^{-1}\right)$ & $5.0 \pm 0.9$ & $5.2 \pm 1.3$ & 0.509 & $5.4 \pm 1.2$ & $5.4 \pm 1.3$ & 0.932 \\
\hline LDL cholesterol $\left(\mathrm{mmoll}^{-1}\right)$ & $2.9 \pm 0.9$ & $3.0 \pm 1.1$ & 0.756 & $3.7 \pm 1.0$ & $3.3 \pm 1.2$ & 0.398 \\
\hline HDL cholesterol $\left(\mathrm{mmol} \mathrm{I}^{-1}\right)$ & $1.3 \pm 0.3$ & $1.4 \pm 0.4$ & 0.517 & $1.5 \pm 0.4$ & $1.6 \pm 0.4$ & 0.468 \\
\hline Triacylglycerides $\left(\mathrm{mmol} \mathrm{I}^{-1}\right)$ & $1.7 \pm 1.0$ & $1.7 \pm 0.7$ & 0.915 & $1.1(0.8-1.9)$ & $1.0(0.8-1.5)$ & 0.533 \\
\hline Fasting plasma glucose $\left(\mathrm{mmol}^{-1}\right)$ & $5.6(4.8-6.2)$ & $5.2(4.4-6.0)$ & 0.209 & $4.8(4.4-5.4)$ & $4.7(4.6-5.4)$ & 0.957 \\
\hline Creatinine $\left(\mu \mathrm{mol} \mathrm{I}{ }^{-1}\right.$ ) & $75 \pm 15$ & $77 \pm 17$ & 0.597 & $60 \pm 10$ & $69 \pm 14$ & 0.039 \\
\hline eGFR $(\mathrm{ml} \mathrm{min}-1)$ & $83 \pm 29$ & $78 \pm 25$ & 0.476 & $103 \pm 28$ & $98 \pm 27$ & 0.792 \\
\hline Smokers $(n ; \%)$ & $4(14 \%)$ & $6(21 \%)$ & - & $2(13 \%)$ & $2(11 \%)$ & - \\
\hline Clinical brachial SBP $(\mathrm{mm} \mathrm{Hg})$ & $136 \pm 17$ & $135 \pm 19$ & 0.711 & $120 \pm 16$ & $118 \pm 14$ & 0.728 \\
\hline Clinical brachial DBP (mm Hg) & $77 \pm 10$ & $74 \pm 10$ & 0.350 & $75 \pm 9$ & $68 \pm 8$ & 0.034 \\
\hline Brachial mean BP (mm Hg) & $99 \pm 11$ & $96 \pm 12$ & 0.385 & $91 \pm 10$ & $85 \pm 10$ & 0.090 \\
\hline Brachial pulse pressure $(\mathrm{mm} \mathrm{Hg})$ & $60 \pm 16$ & $60 \pm 14$ & 0.869 & $45 \pm 10$ & $50 \pm 10$ & 0.182 \\
\hline Heart rate $(\mathrm{bpm})$ & $70 \pm 8$ & $70 \pm 13$ & 0.942 & $72 \pm 8$ & $66 \pm 8$ & 0.089 \\
\hline Pulse wave velocity $\left(\mathrm{m} \mathrm{s}^{-1}\right)$ & $10.06 \pm 2.54$ & $8.48 \pm 2.03$ & 0.013 & $7.6 \pm 1.8$ & $5.83 \pm 0.88$ & $<0.001$ \\
\hline
\end{tabular}

Abbreviations: BML, body mass index; eGFR, estimated glomerular filtration rate; EH, essential hypertension patients; $\mathrm{HDL}$, high-density lipoprotein; iPTH; serum-intact parathyroid hormone; LDL, low-density lipoprotein; NCS, normotensive control subjects; PHHT, patients with primary hyperparathyroidism and concomitant hypertension; PHNT, primary hyperparathyroidism patients without hypertension.

Values are shown as means \pm s.d. or medians (interquartile range) or absolute numbers and percentages. Variables are compared by unpaired $t$-test or Kruskal-Wallis test where appropriate. 


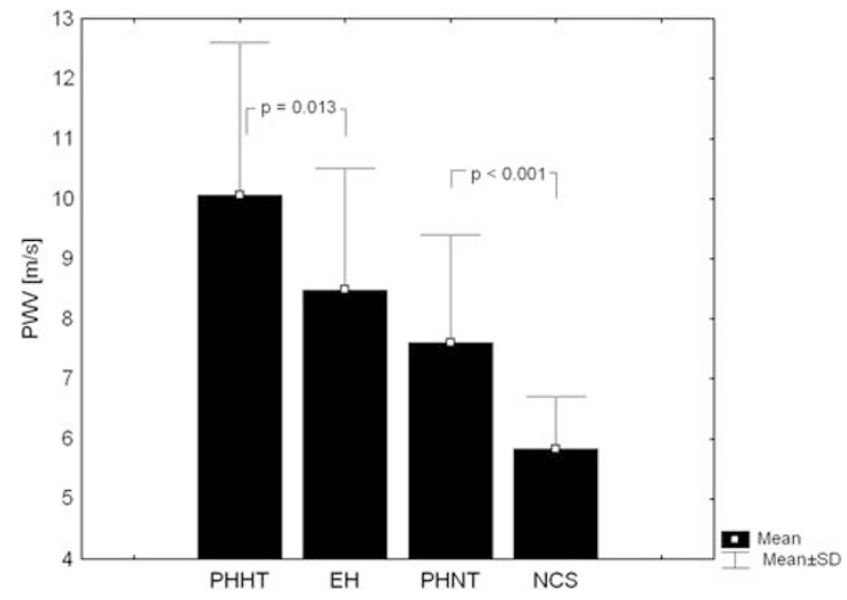

Figure 1 PWV-PHHT vs. EH; PHNT vs. NCS. EH, essential hypertension patients; NCS, normotensive control subjects; PHHT, patients with primary hyperparathyroidism and concomitant hypertension; PHNT, primary hyperparathyroidism patients without hypertension; PWV, pulse wave velocity.

Table 2 Simple regression analysis and multivariate regression analysis using PWV as dependent variable for (a) PHHT (b) PHNT

\begin{tabular}{|c|c|c|c|c|}
\hline & \multicolumn{2}{|c|}{ Simple regression } & \multicolumn{2}{|c|}{ Multiple regression } \\
\hline & r & P-value & $\beta$ & P-value \\
\hline \multicolumn{5}{|l|}{ (a) } \\
\hline Duration of hypertension (years) & 0.4317 & 0.045 & - & - \\
\hline Age (years) & 0.5758 & 0.001 & 0.4408 & 0.0090 \\
\hline Clinical brachial SBP (mm Hg) & 0.5699 & 0.002 & 0.2344 & 0.2077 \\
\hline Brachial mean BP $(\mathrm{mm} \mathrm{Hg})$ & 0.4225 & 0.025 & - & - \\
\hline Brachial pulse pressure $(\mathrm{mm} \mathrm{Hg})$ & 0.6334 & $<0.001$ & - & - \\
\hline Plasma phosphorous (mmol $\mathrm{I}^{-1}$ ) & 0.3855 & 0.043 & - & - \\
\hline Fasting plasma glucose $\left(\mathrm{mmol} \mathrm{I}^{-1}\right)$ & 0.6660 & $<0.001$ & 0.4419 & 0.026 \\
\hline \multicolumn{5}{|l|}{ (b) } \\
\hline Age (years) & 0.5816 & 0.018 & 0.4466 & 0.023 \\
\hline BMI $\left(\mathrm{kg} \mathrm{m}^{-2}\right)$ & 0.5926 & 0.016 & - & - \\
\hline Clinical brachial DBP $(\mathrm{mm} \mathrm{Hg})$ & 0.5191 & 0.039 & 0.2226 & 0.159 \\
\hline Total plasma cholesterol $\left(\mathrm{mmol} \mathrm{I}^{-1}\right)$ & 0.6184 & 0.014 & 0.2083 & 0.189 \\
\hline Triacylglycerides $\left(\mathrm{mmol} \mathrm{I}^{-1}\right)$ & 0.7452 & 0.001 & 0.4050 & 0.082 \\
\hline
\end{tabular}

Abbreviations: $\beta$, multiple regression analysis coefficient; $\mathrm{BMI}$, body mass index; $\mathrm{BP}$, blood pressure; DBP, diastolic blood pressure; PHHT, patients with primary hyperparathyroidism and concomitant hypertension; PHNT, primary hyperparathyroidism patients without hypertension; PWV, pulse wave velocity; r, Pearson's correlation coefficient; SBP, systolic blood pressure.

$74 \mathrm{~mm} \mathrm{Hg}, P=0.71 / 0.35)$ was found. The difference in PWV remained significant even after adjusting for age and mean $\mathrm{BP}(P=0.02$; the results were comparable when adjusted for systolic or diastolic BP). Similarly, PWV was significantly higher in the PHNT group when compared with the normotensive control subject group (7.6 vs. $\left.5.8 \mathrm{~m} \mathrm{~s}^{-1}, P<0.001\right)$. This difference remained significant even after adjusting for age and mean $\mathrm{BP}(P=0.003$; the results were comparable when adjusted for systolic and diastolic BP). The results are illustrated in a categorized scatterplot (Figure 1).
Table 3 Characteristics of 15 (11 PHHT and 4 PHNT) studied subjects before and 6 months after PTX

\begin{tabular}{|c|c|c|c|}
\hline & Before & After & P-value \\
\hline Age (years) & & $63 \pm 12$ & \\
\hline $\mathrm{BMI}\left(\mathrm{kg} \mathrm{m}^{-2}\right)$ & $27.2 \pm 4.7$ & $27.3 \pm 4.8$ & 0.844 \\
\hline Plasma sodium $\left(\mathrm{mmol}^{-1}\right)$ & $141 \pm 3$ & $141 \pm 3$ & 0.937 \\
\hline Plasma potassium $\left(\mathrm{mmol} \mathrm{I}^{-1}\right)$ & $4.4 \pm 0.3$ & $4.3 \pm 0.5$ & 0.099 \\
\hline Plasma chloride $\left(\mathrm{mmol} \mathrm{I}^{-1}\right)$ & $106 \pm 3$ & $104 \pm 3$ & 0.028 \\
\hline Plasma calcium $\left(\mathrm{mmoll}^{-1}\right)$ & $2.82 \pm 0.23$ & $2.14 \pm 0.23$ & $<0.001$ \\
\hline Plasma phosphorous (mmol $\mathrm{I}^{-1}$ ) & $0.83 \pm 0.16$ & $1.13 \pm 0.26$ & $<0.005$ \\
\hline iPTH $\left(p^{\prime}\right.$ l I I $\left.^{-1}\right)$ & $19.5 \pm 17.1$ & $2.9 \pm 1.6$ & $<0.005$ \\
\hline Total plasma cholesterol $\left(\mathrm{mmol} \mathrm{I}^{-1}\right)$ & $4.7 \pm 1.1$ & $5.2 \pm 1.0$ & 0.114 \\
\hline LDL cholesterol (mmol $\left.\mathrm{I}^{-1}\right)$ & $2.9 \pm 1.0$ & $3.1 \pm 0.9$ & 0.432 \\
\hline $\mathrm{HDL}$ cholesterol $\left(\mathrm{mmoll}^{-1}\right)$ & $1.3 \pm 0.4$ & $1.3 \pm 0.3$ & 0.908 \\
\hline Triacylglycerides $\left(\mathrm{mmol}^{-1}\right)$ & $1.2(1.0-1.9)$ & $1.2(0.9-1.5)$ & 0.859 \\
\hline Fasting plasma glucose $\left(\mathrm{mmol}^{-1}\right)$ & $5.2 \pm 0.9$ & $5.7 \pm 1.5$ & 0.246 \\
\hline Creatinine $\left(\mu \mathrm{mol} \mathrm{I}^{-1}\right)$ & $68 \pm 12$ & $76 \pm 18$ & 0.054 \\
\hline eGFR $(\mathrm{ml} \mathrm{min}-1)$ & $89 \pm 32$ & $83 \pm 33$ & 0.065 \\
\hline Clinical brachial SBP $(\mathrm{mm} \mathrm{Hg})$ & $131 \pm 20$ & $123 \pm 18$ & 0.004 \\
\hline Clinical brachial DBP $(\mathrm{mm} \mathrm{Hg})$ & $75 \pm 13$ & $75 \pm 11$ & 0.922 \\
\hline Brachial mean BP $(\mathrm{mm} \mathrm{Hg})$ & $94 \pm 14$ & $91 \pm 12$ & 0.276 \\
\hline Brachial pulse pressure $(\mathrm{mm} \mathrm{Hg})$ & $56 \pm 13$ & $48 \pm 12$ & 0.001 \\
\hline Heart rate (bpm) & $69 \pm 9$ & $68 \pm 10$ & 0.659 \\
\hline Pulse wave velocity $\left(\mathrm{m} \mathrm{s}^{-1}\right)$ & $9.05 \pm 1.81$ & $8.54 \pm 1.79$ & 0.024 \\
\hline
\end{tabular}

Abbreviations: BMI, body mass index; BP, blood pressure; DBP, diastolic blood pressure; eGFR, estimated glomerular filtration rate; HDL, high-density lipoprotein; iPTH; serum-intact parathyroid hormone; LDL, low-density lipoprotein; PHHT, patients with primary hyperparathyroidism and concomitant hypertension; PHNT, primary hyperparathyroidism patients without hypertension; PTX, parathyroidectomy; SBP, systolic blood pressure. Values are shown as means \pm s.d. or medians (interquartile range). Variables are compared by paired $t$-test or Wilcoxon's pair test where appropriate.

In PHHT patients, PWV univariately correlated with duration of hypertension, age, systolic and mean blood pressure, pulse pressure, plasma phosphates and fasting glucose. In the multivariate regression analysis, PWV significantly correlated only with age $(\beta=0.441$, $P<0.01)$ and fasting glucose level $(\beta=0.442, P<0.05)$. In the PHNT group, PWV univariately correlated with age, body mass index, diastolic BP, total cholesterol and level of triglycerides. In multivariate regression analysis, PWV significantly correlated only with age $(\beta=0.447, P<0.05)$. The results are shown in Table 2 .

Table 3 summarizes the characteristics of 15 subjects with $\mathrm{PH}$ (hypertensive as well as normotensive) who underwent surgical treatment. Six months after surgery, in addition to normalization of calcium metabolism, significant decreases in systolic BP (131 vs. $123 \mathrm{~mm} \mathrm{Hg}, P=0.004$ ), pulse pressure ( 56 vs. $48 \mathrm{~mm} \mathrm{Hg}, P=0.001$ ) and PWV (9.1 vs. $\left.8.5 \mathrm{~m} \mathrm{~s}^{-1}, P=0.024\right)$ were observed; treatment with antihypertensive medication was not intensified. After adjustment for $\mathrm{BP}$ reduction, the decrease in PWV appeared to be non-significant $(P=0.12)$. Surprisingly, serum creatinine increased and estimated glomerular filtration rate decreased after surgery (both with borderline statistical significance).

\section{DISCUSSION}

Our study demonstrated higher aortic stiffness, as determined by $\mathrm{PWV}$, in both hypertensive and normotensive subjects with $\mathrm{PH}$ when compared with age-matched patients with $\mathrm{EH}$ and normotensive control subjects, respectively. BP and age are considered to be the main determinants of PWV. ${ }^{13}$ Even if both pairs of studied groups were comparable in terms of BP and age, PWV was adjusted for these confounders in the multivariate model. The difference in PWV 
remained significantly higher in both normotensive and hypertensive patients with $\mathrm{PH}$. Our findings of higher $\mathrm{PWV}$ in $\mathrm{PH}$ hypertensive subjects compared with normotensive counterparts, as well as the BP and PWV decrease after PTX, support the fact that BP may be the primary determinant of PWV. Yet, we found higher PWV in both hypertensive and normotensive $\mathrm{PH}$ patients when compared with $\mathrm{EH}$ or normotensive control subjects with comparable BP levels. Moreover, the fact that PWV did not correlate with BP using multivariate regression analysis suggests that a higher $\mathrm{BP}$ might not be the only mechanism of increased arterial stiffness in PH. Calcium and/or PTH changes may also play a role in higher aortic stiffness in $\mathrm{PH}$. Disturbances in calcium metabolism/PTH may enhance catecholamine secretion, induce activation of the renin-angiotensin-aldosterone system, or induce vasoconstriction or sensitivity of the wall vessel in response to vasoconstrictor substances. ${ }^{4}$ Hypercalcemia has been associated with hypertension, left ventricular hypertrophy, arrhythmias and vasoconstriction, as well as calcification of the myocardium, heart valves, coronary arteries and carotid plaque thickness. ${ }^{18}$ Both serum calcium level and PTH have been reported as risk factors for coronary heart disease. ${ }^{19}$ In our study, neither calcium serum levels nor PTH levels were associated with PWV. Different effects of PTH on the vasculature, including vasodilatation or vasoconstriction, have been observed. ${ }^{20}$ In a recent study, a positive correlation of PTH with elevated levels of aldosterone has been reported ${ }^{21}$ and thus differences in plasma aldosterone levels may also play a role. However, in previous studies, no similar correlation of PTH with aldosterone was observed and, furthermore, there were no differences in aldosterone levels before and after surgery in patients with $\mathrm{PH} .{ }^{22}$ In another study, PTH levels were closely correlated with intracellular but not with total serum calcium levels. ${ }^{2}$ Thus, PTH may act as an ionophore for the entry of calcium into the cell. PTH might stimulate the endothelial expression of proatherosclerotic and proinflammatory markers, impair smooth muscle cell relaxation and/or act as a hypertrophic factor on vascular smooth muscle and myocardial cells. $^{23}$ Therefore, PTH may indirectly affect aortic stiffness in $\mathrm{PH}$. Increased arterial stiffness in $\mathrm{PH}$ may thus result from either structural (for example, arterial wall calcification) or functional (for example, endothelial) abnormalities in large- and medium-sized vessels or a combination of both factors. However, functional changes seem to be crucial. $^{18}$

$\mathrm{PH}$ might lead to a deterioration of renal function. Apart from the effects of hypercalcemia (nephrolithiasis- or nephrocalcinosis-induced nephropathy), direct effects of PTH have been discussed. PTH might affect the renal microcirculation through the influence of renal blood flow, glomerular filtration rate and excretory functions. ${ }^{20,24}$ The exact mechanism of the PTH-mediated effect on renal blood flow is not clear, as both vasodilatory and vasoconstrictive effects of PTH on glomerular vessels have been described. ${ }^{20}$ PTX is usually associated with renal function improvement, ${ }^{1}$ but renal functional impairment after PTX is rarely described in the literature. ${ }^{20}$ Although we observed mild increases in serum creatinine and decreases in estimated glomerular filtration rate after surgery (with borderline statistical significance), our population lacked patients with the manifestation of renal failure. We believe that these insignificant results could be influenced either by a relatively small number of post-PTX subjects or other contributory cofactors. The decrease in PTH after PTX with changes in renal blood flow might be responsible for the acute alteration of renal function. ${ }^{20}$ In the long term, however, these hemodynamic changes may contribute to attenuation of the progression of renal failure. As our patients were followed up for only 6 months after surgery, we were not able to assess long-term effects of
PTX among our subject population. We assume that renal function will subsequently improve and that the slight impairment of renal function that we observed was only temporary. ${ }^{20} \mathrm{We}$ also believe that further studies focusing on this particular topic are needed. Our study, however, was not designed to be a complex evaluation of renal function before and after PTX.

Our results are in line with previous studies, which suggest that PTX might improve BP control, ${ }^{3,25}$ left ventricular diastolic dysfunction, cardiac irritability and myocardial ischemia, as well as reduce overall cardiovascular risk. ${ }^{3,25}$ Yet, there are studies with contradictory results, suggesting that PTX might not be beneficial to control $\mathrm{BP}{ }^{14,26}$ improve arterial stiffness ${ }^{12}$ or reduce cardiovascular risk. ${ }^{14}$ Aside from levels of calcium and PTH, the harmful effects of a hyperparathyroid condition also depend on disease duration. This variable is not examined in the clinical studies enrolling populations with varying disease severity. Moreover, different study methodologies have been used. Another explanation for different results might be the relatively small sample of subjects in our study, because of the relative rareness of $\mathrm{PH}$, and this fact is one of the possible limitations of our study. A longitudinal investigation of a large sample of patients with $\mathrm{PH}$, with ambulatory BP monitoring before and after PTX in PH, is obviously necessary. Another possible limitation of our study is different antihypertensive treatments in the $\mathrm{PH}$ and $\mathrm{EH}$ groups, which may have resulted in varying effects on PWV. However, there were no significant differences in BP. Furthermore, because doxazosin has no effect and verapamil has only a slight effect on $\mathrm{PWV},{ }^{27}$ various antihypertensive treatments in the $\mathrm{PH}$ group were only able to decrease PWV.

In conclusion, the present study demonstrates that $\mathrm{PH}$ might be associated with higher arterial stiffness (represented by carotidfemoral PWV) when compared with $\mathrm{EH}$ patients or normotensive controls, and that this difference is independent of age and clinical blood pressure. Neither calcium serum levels nor PTH levels have been associated with PWV. Specific treatment by PTX seems to be beneficial in decreasing PWV, which may result from improved BP control after surgery. As PTX indications for asymptomatic forms of $\mathrm{PH}$ have been discussed, ${ }^{17,28}$ our data suggest the potential benefit pursuant to a reduction of subclinical organ damage after surgical treatment in these patients.

\section{CONFLICT OF INTEREST}

The authors declare no conflict of interest.

\section{ACKNOWLEDGEMENTS}

This study was supported by research projects of the Ministry of Education of Czech Republic, nos. 21620817 and 21620807.

1 Marx SJ. Hyperparathyroid and hypoparathyroid disorders. N Engl J Med 2000; 343 : 1863-1875.

2 Fardella C, Rodriguez-Portales JA. Intracellular calcium and blood pressure: comparison between primary hyperparathyroidism and essential hypertension. J Endocrinol Invest 1995; 18: 827-832.

3 Hedback GM, Oden AS. Cardiovascular disease, hypertension and renal function in primary hyperparathyroidism. J Intern Med 2002; 251: 476-483.

4 Gennari C, Nami R, Gonnelli S. Hypertension and primary hyperparathyroidism: the role of adrenergic and renin-angiotensin-aldosterone systems. Miner Electrolyte Metab 1995; 21: 77-81.

5 Andersson P, Rydberg E, Willenheimer R. Primary hyperparathyroidism and heart disease; a review. Eur Heart J 2004; 25: 1776-1787.

6 Walker MD, Fleischer J, Rundek T, McMahon DJ, Homma S, Sacco R, Silverberg SJ. Carotid vascular abnormalities in primary hyperparathyroidism. J Clin Endocrinol Metab 2009; 94: 3849-3856. 
7 Fallo F, Cella G, Casonato A, Ermani M, Vettor R, Zanella S, Lumachi F. Biochemical markers of endothelial activation in primary hyperparathyroidism. Horm Metab Res 2006; 38: 125-129.

8 Baykan M, Erem C, Erdogan T, Hacihasanoğlu A, Gedikli O, Kiriş A, Küçükosmanoğlu M, Ersöz HO, Celik S. Impairment of flow mediated vasodilatation of brachial artery in patients with primary hyperparathyroidism. Int J Cardiovasc Imaging 2007; 23: 323-328.

9 Smith JC, Page MD, John R, Wheeler MH, Cockcroft JR, Scanlon MF, Davies JS. Augmentation of central arterial pressure in mild primary hyperparathyroidism. J Clin Endocrinol Metab 2000; 85: 3515-3519.

10 Rubin MR, Maurer MS, McMahon DJ, Bilezikian JP, Silverberg SJ. Arterial stiffness in mild primary hyperparathyroidism. J Clin Endocrinol Metab 2005; 90: 3326-3330.

11 Bitigen A, Tanalp AC, Kaynak E, Karavelioglu Y, Kirma C, Adas M, Yilmaz MB. Elastic properties of aorta in patients with primary hyperparathyroidism. Int J Clin Pract 2006; 60: 1572-1575.

12 Kosch M, Hausberg M, Barenbrock M, Posadzy-Malaczynska A, Kisters K, Rahn KH. Arterial distensibility and pulse wave velocity in patients with primary hyperparathyroidism before and after parathyroidectomy. Clin Nephrol 2001; 55: 303-308.

13 Mitchell GF, Hwang SJ, Vasan RS, Larson MG, Pencina MJ, Hamburg NM, Vita JA, Levy D, Benjamin EJ. Arterial stiffness and cardiovascular events: the Framingham Heart Study. Circulation 2010; 121: 505-511.

14 Bollerslev J, Rosen T, Mollerup CL, Nordenström J, Baranowski M, Franco C, Pernow Y, Isaksen GA, Godang K, Ueland T, Jansson S. Effect of surgery on cardiovascular risk factors in mild primary hyperparathyroidism. J Clin Endocrinol Metab 2009; 94: 2255-2261.

15 Fitzpatrick LA, Bilezikian JP, Silverberg SJ. Parathyroid hormone and the cardiovascular system. Curr Osteoporos Rep 2008; 6: 77-83.

16 Richards AM, Espiner EA, Nicholls MG, Ikram H, Hamilton EJ, Maslowski AH. Hormone, calcium and blood pressure relationships in primary hyperparathyroidism. J Hypertens 1988; 6: 747-752.

17 Bilezikian JP, Khan AA, Potts Jr JT. Guidelines for the management of asymptomatic primary hyperparathyroidism: summary statement from the third international workshop. J Clin Endocrinol Metab 2009; 94: 335-339.
18 Walker MD, Silverberg SJ. Cardiovascular aspects of primary hyperparathyroidism. J Endocrinol Invest 2008; 31: 925-931.

19 Kamycheva E, Sundsfjord J, Jorde R. Serum parathyroid hormone levels predict coronary heart disease: the Tromso Study. Eur J Cardiovasc Prev Rehabil 2004; 11: 69-74.

20 Montenegro FL, Martin RM, Correa PH. Renal failure after surgery for primary hyperparathyroidism: is acute reduction of parathyroid function a risk factor? Clinics (Sao Paulo, Brazil) 2009; 64: 369-372.

21 Brunaud L, Germain A, Zarnegar R, Zarnegar R, Rancier M, Alrasheedi S, Caillard C, Ayav A, Weryha G, Mirallie E, Bresler L. Serum aldosterone is correlated positively to parathyroid hormone (PTH) levels in patients with primary hyperparathyroidism. Surgery 2009; 146: 1035-1041.

22 Bernini G, Moretti A, Lonzi S, Bendinelli C, Miccoli P, Salvetti A. Renin-angiotensinaldosterone system in primary hyperparathyroidism before and after surgery. Metabolism 1999; 48: 298-300.

23 Rashid G, Bernheim J, Green J, Benchetrit S. Parathyroid hormone stimulates the endothelial expression of vascular endothelial growth factor. Eur J Clin Invest 2008; 38: 798-803.

24 Massfelder T, Parekh N, Endlich K, Saussine C, Steinhausen M, Helwig JJ. Effect of intrarenally infused parathyroid hormone-related protein on renal blood flow and glomerular filtration rate in the anaesthetized rat. $\mathrm{Br} J$ Pharmacol 1996; 118: 1995-2000.

25 Ringe JD. Reversible hypertension in primary hyperparathyroidism: pre- and posteroperative blood pressure in 75 cases. Klin Wochenschr 1984; 62: 465-469.

26 Sancho JJ, Rouco J, Riera-Vidal R, Sitges-Serra A. Long-term effects of parathyroidectomy for primary hyperparathyroidism on arterial hypertension. World J Surg 1992; 16: 732-735; discussion 736 .

27 Mahmud A. Reducing arterial stiffness and wave reflection-Quest for the Holy Grail? Artery Res 2007; 1: 13-19.

28 Sitges-Serra A, Rosa P, Valero M, Membrilla E, Sancho JJ. Surgery for sporadic primary hyperparathyroidism: controversies and evidence-based approach. Langenbecks Arch Surg 2008; 393: 239-244. 